\title{
A new method to quantify coronary flow conditions using dynamically scaled in vitro phase contrast magnetic resonance imaging
}

\author{
Susann Beier ${ }^{1 *}$, John Ormiston², Mark Webster ${ }^{3}$, John Cater ${ }^{4}$, Stuart Norris $^{4}$, Pau Medrano-Gracia ${ }^{1}$, Alistair Young ${ }^{1}$, \\ Brett R Cowan'
}

From 19th Annual SCMR Scientific Sessions

Los Angeles, CA, USA. 27-30 January 2016

\section{Background}

Atherosclerotic coronary artery disease remains a major cause of illness and death, and coronary flow predetermines disease. Limitations in imaging technology prevent coronary flow measurements but computational fluid dynamics (CFD) need sophisticated boundary conditions for accurate flow predictions. MRI has recently been combined with CFD for larger calibre vessels, but small coronary arteries remain inaccessible.
The aim of this study was to assess the feasibility of coronary flow measurement in 3D printed large scale coronary phantoms using phase contrast MRI (PC-MRI).

\section{Methods}

1) Three patient bifurcation geometries with $33^{\circ}, 72^{\circ}$ and $110^{\circ}$ angle (mean and $\pm 2 \mathrm{SD}$ of the first principal mode of variation of 300 asymptomatic patients) were 2) 6:1 printed, and their flow was replicated via a dynamically scaled blood mimicking flow circuit. The PC-MRI

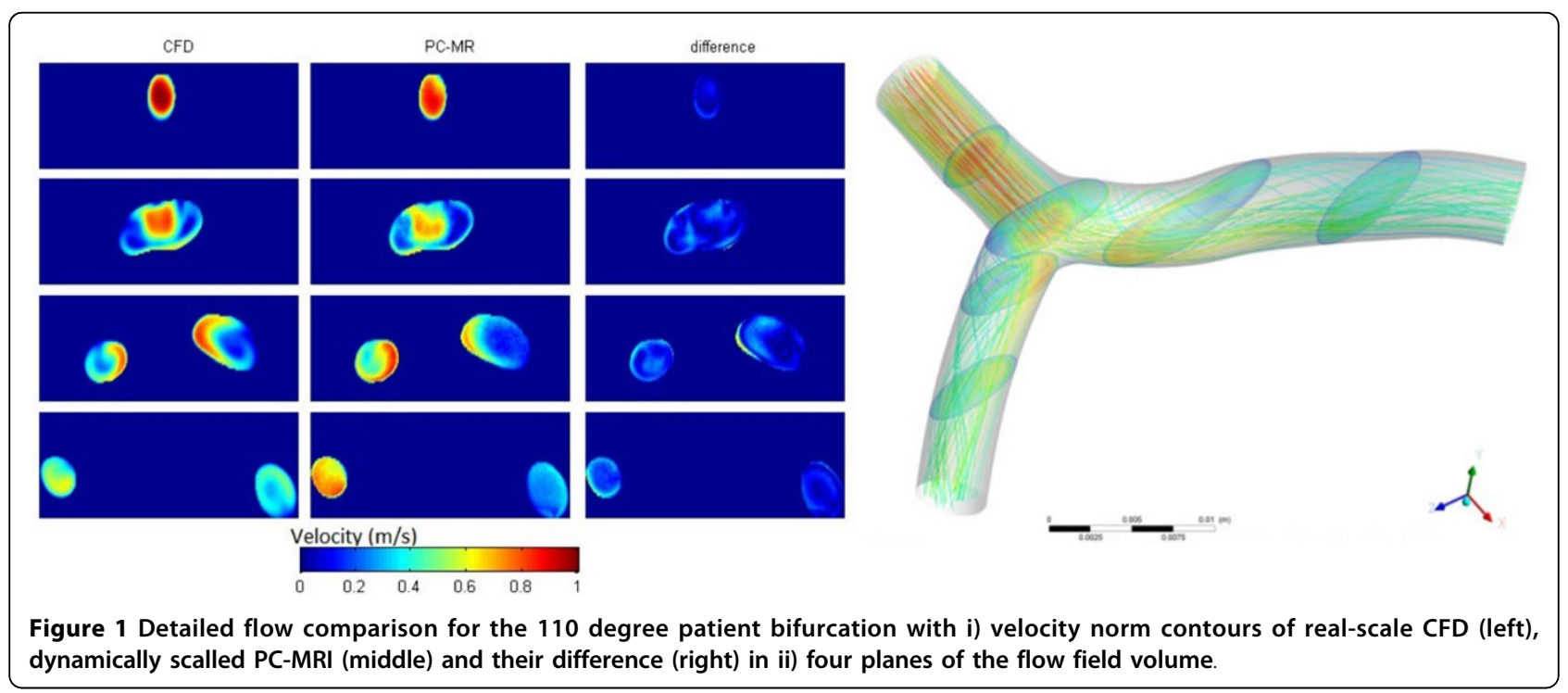

${ }^{1}$ Anatomy with Radiology, Auckland University, Auckland, New Zealand

Full list of author information is available at the end of the article

(c) 2016 Beier et al. This is an Open Access article distributed under the terms of the Creative Commons Attribution License (http:// 
measured flow was measured was semi-automatically segmented and co-registered to 3) identical, real scale CFD. Measured velocity inlets profiles were transformed and prescribed as CFD inlet condition. The data was statistically compared using a 3D flow field correlation analysis.

\section{Results}

Coronary flow was successfully replicated and measured with dynamically scaled 3D printed phantom PC-MRI, where co-registration $(\sigma<5 \mathrm{e}-6)$ resulted in good to strong agreement in magnitude (error $2-12 \%, \rho \geq 0.72$ ), and direction $\left(r^{2} \geq 0.74\right)$.

\section{Conclusions}

We have successfully developed, validated and applied a new method to quantify coronary haemodynamics by combining enlarged 3D printed PC-MRI flow with CFD simulations. With this methodology, the PC-MRI measurements can be used to define accurate boundary conditions to elevate CFD simulations and ultimate improve predictions about stent design, coronary artery risk assessment and clinical practice. PC-MRI is non-invasive, accurate imaging technology and has the potential to become an important measurement tool to aid early CFD detection of cardiovascular disease, to risk stratify and optimise treatment for individual patients.

\section{Authors' details}

${ }^{1}$ Anatomy with Radiology, Auckland University, Auckland, New Zealand ${ }^{2}$ Mercy Angiography, Auckland, New Zealand. ${ }^{3} \mathrm{ADHB}$, Auckland, New Zealand. ${ }^{4}$ Engineering Sciences, Faculty of Engineering, Auckland, New Zealand.

Published: 27 January 2016
doi:10.1186/1532-429X-18-S1-P103

Cite this article as: Beier et al:: A new method to quantify coronary flow conditions using dynamically scaled in vitro phase contrast magnetic resonance imaging. Journal of Cardiovascular Magnetic Resonance 201618 (Suppl 1):P103.
Submit your next manuscript to BioMed Central and take full advantage of:

- Convenient online submission

- Thorough peer review

- No space constraints or color figure charges

- Immediate publication on acceptance

- Inclusion in PubMed, CAS, Scopus and Google Scholar

- Research which is freely available for redistribution

Submit your manuscript at www.biomedcentral.com/submit 